\title{
Practical Artificial Ventilation in an African Tropical Environment: Experience of the Intensive Care Unit of the University Hospital of Treichville
}

\author{
Irié Bi Gohi Serge ${ }^{1^{*}}$, Ango Privat Désiré2, Netro Djohoui ${ }^{3}$, Pete Yaich ${ }^{1}$, Nabintou Koné2 \\ Kouadio Konan Stéphanie1, Ogondon Bernard ${ }^{1}$, Able Edmond ${ }^{1}$, Boua Narcisse ${ }^{1}$, Brouh Yapo ${ }^{1}$ \\ ${ }^{1}$ Resuscitation Department, University Hospital Center of Bouake, Bouake, Ivory Coast \\ ${ }^{2}$ Resuscitation Department, University Hospital Center of Treichville, Abidjan, Ivory Coast \\ ${ }^{3}$ Resuscitation Department, University Hospital Center of Cocody, Abidjan, Ivory Coast \\ Email: *iriebi_gohiserge@yahoo.fr
}

How to cite this paper: Serge, I.B.G., Désiré, A.P., Djohoui, N., Yaich, P., Koné, N., Stéphanie, K.K., Bernard, O., Edmond, A., Narcisse, B. and Yapo, B. (2018) Practical Artificial Ventilation in an African Tropical Environment: Experience of the Intensive Care Unit of the University Hospital of Treichville. Open Journal of Anesthesiology, 8, 123-129.

https://doi.org/10.4236/ojanes.2018.84013

Received: March 24, 2018

Accepted: April 24, 2018

Published: April 27, 2018

Copyright $\odot 2018$ by authors and Scientific Research Publishing Inc. This work is licensed under the Creative Commons Attribution International License (CC BY 4.0).

http://creativecommons.org/licenses/by/4.0/

\section{(c) (i) Open Access}

\begin{abstract}
Objective: To describe the practice of artificial ventilation (VA) in a resuscitation unit of a developing country with a view to its improvement. Patients and Methods: Prospective study for descriptive and analytical purposes, carried out in the intensive care unit of the University and Hospital Center of Treichville (Ivory Coast) from April 2009 to June 2010. All the patients having benefited from a artificial ventilation for a duration greater than 6 hours were included in this study. The studied parameters were: Socio-demographic (age, sex), diagnostic, therapeutic (indications, duration and complications of artificial ventilation), evolutionary. Results: Out of a total of 204 admissions during the study period, 81 patients received artificial ventilation, an incidence of artificial ventilation in the order of $39.7 \%$. There were 49 men and 32 women. The ventilated patients had an average age of 43.9 years (range: 4 years and 85 years). Pathologies requiring artificial ventilation were neurological $(46 \%)$ and traumatic (28\%). Stroke was the leading medical condition (65\%) while polytrauma was the major traumatic condition (65\%). The most commonly used ventilatory modes were controlled volume ventilation (52.4\%) and assisted ventilation (34.9\%). The mean duration of artificial ventilation was $5.98 \pm 3.73$ days (range: 1 day and 21 days). The nosocomial pneumonia acquired under mechanical ventilation (PAVM) constituted $27 \%$ of the complications observed under artificial ventilation. The average length of ICU stay for all ventilated patients was $9.85+/-7.51$ days (range: 1 day and 31 days). The lethality in our series was $80 \%$. Patient age was the only prog-
\end{abstract}


nostic factor associated with death $(\mathrm{P}=0.003)$. Conclusion: The practice of artificial ventilation is still difficult in Ivory Coast and is at the origin of many complications such as nosocomial pneumonia acquired under mechanical ventilation which complicate the life threatening of the patients.

\section{Keywords}

Artificial Ventilation, Resuscitation, Complications, Ivory Coast

\section{Introduction}

Artificial ventilation is one of the basic ICU techniques used to treat neurological and respiratory failures. It is estimated that $35 \%$ of patients admitted to intensive care units have artificial ventilation [1]. Since 1950, many advances have been made in the field of artificial ventilation making its practice easy and unavoidable in many Western countries. In the United States, 790,000 patients per year benefit from artificial ventilation, representing $2.8 \%$ of all inpatients [2]. In developing countries, and particularly in tropical environments, the practice of artificial ventilation remains difficult [3]. This is due to many problems related to: a shortage of equipment, a weakness of economic resources, scarcity of qualified personnel and a lack of suitable equipment [3]. Despite all these difficulties, artificial ventilation remains an indispensable tool in the management of respiratory and neurological failures in intensive care units in tropical environments. Although artificial ventilation often saves lives, it can cause many complications that can be deleterious to patients [4]. In Ivory Coast, data on the achievement of artificial ventilation in intensive care unit are rare. The purpose of this study was to describe the practice of artificial ventilation in the intensive care unit of the University Hospital of Treichville with a view to coming up with recommendations for its improvement.

\section{Patients and Methods}

This was a descriptive and prospective study conducted over a period of 9 months (April 2009 to June 2010) in the intensive care unit of the University Hospital of Treichville. The intensive care unit of the University Hospital of Treichville is the 3rd Resuscitation Department of the city of Abidjan. It has a capacity of eight beds each with a respirator to achieve a artificial ventilation. All patients placed on artificial ventilation for more than 6 hours regardless of age and artificial ventilation pattern were included in this study. Patients whose artificial ventilation duration was less than 6 hours, and those evacuated to another health facility before extubation were not excluded. Data collection was performed from a pre-established survey form. The parameters studied given were: socio-demographic data (age, sex), the main diagnosis, characteristics of artificial ventilation (indications, duration, complications, and duration), length of 
stay in intensive care and evolution. The different parameters studied were collected on a computer support (Excel 2000 and Systat 8.0 software). The statistical tests used were Khi2 for non-quantitative data and the Student's test for quantitative data. A value of $p<0.05$ was selected as statistically significant.

\section{Results}

Of the 204 patients hospitalized during the study period, 81 had mechanical ventilation, or $39.7 \%$ of admitted patients. The sex ratio (male/female) was 1.38 . The subjects aged between 30 and 44 years were the most likely to have had artificial ventilation (23.4\%) (Table 1). The mean age of ventilated patients was $43.98 \pm$ 20.69 (range: 4 years and 85 years). The major medical history of the patients was high blood pressure (37\%) and diabetes (16\%). Respiratory history was observed in only $6 \%$ of patients. The conditions requiring artificial ventilation patients to be placed were mainly neurological $(44.2 \%)$ and traumatic $(28,5 \%)$ (Table 2). Stroke was the leading medical condition (65\%) while polytrauma was the major traumatic condition (65\%) (Table 2). The orotracheal intubation route was used in $68.3 \%$ of patients. Artificial ventilation was performed with sedation in $95 \%$ of subjects. In $69 \%$ of cases, sedation was performed with fentanyl-diazepam. The most commonly used ventilatory modes were controlled volume ventilation (52.4\%) and assisted ventilation (34.9\%). In 54\% of cases, the duration of the artificial ventilation was between 1 and 5 days (Table 3). The mean duration of artificial ventilation was $5.98 \pm 3.73$ days (range: 1 day to 21 days). Nosocomial pneumonia acquired with mechanical ventilation (27\%) was the main complication observed in patients with artificial ventilation (Table 4). The average length of ICU stay for all ventilated patients was $9.85+/-7.51$ days (range: 1 day and 31 days). The lethality in our series was $80 \%$. The poor prognostic factor associated with mortality was age $(\mathrm{P}=0.003)$ (Table 5$)$.

\section{Discussion}

Studies of artificial ventilation in developing countries are few in number because of inadequate facilities for resuscitation and their frequent state of human and material deprivation. The incidence of artificial ventilation in our study was

Table 1. Distribution of Patients by Age $(n=81)$.

\begin{tabular}{ccc}
\hline Age (year) & Number & Percentage (\%) \\
\hline $0-14$ year old & 09 & 11.1 \\
$15-29$ year old & 13 & 16 \\
$30-44$ year old & 19 & 23.4 \\
$45-59$ year old & 17 & 21 \\
$60-74$ year old & 17 & 21 \\
$>75$ year old & 06 & 7.4 \\
\hline
\end{tabular}


Table 2. Distribution of patients according to pathologies requiring artificial ventilation $(\mathrm{n}=81)$.

\begin{tabular}{|c|c|c|c|}
\hline \multicolumn{2}{|c|}{ Medical conditions } & Number & Percentage \\
\hline \multirow{3}{*}{ Neurological pathologies } & Cerebrovascular accident & 27 & 33.3 \\
\hline & Epilepsy & 02 & 2.4 \\
\hline & Meningoencephalitis & 05 & 6.1 \\
\hline & Eclampsia & 02 & 2.4 \\
\hline Respiratory diseases & Lung cancer & 01 & 1.2 \\
\hline \multirow{2}{*}{ Infectieuses diseases } & Septic shock & 10 & 12.3 \\
\hline & Severe malaria & 02 & 2.4 \\
\hline Metabolic pathologies & Diabetic ketoacidosis & 01 & 1.2 \\
\hline Toxic & Organophosphorus poisoning & 02 & 2.4 \\
\hline \multicolumn{2}{|c|}{ Surgical pathologies } & Number & Percentage \\
\hline \multirow{2}{*}{ Traumatic } & Severe head trauma & 15 & 18.5 \\
\hline & Polytrauma & 08 & 10 \\
\hline Other & postoperative cerebral anoxia & 06 & 7.4 \\
\hline
\end{tabular}

Table 3. Distribution of patients by duration of artificial ventilation $(n=81)$.

\begin{tabular}{ccc}
\hline Duration (days) & Number & Percentage \\
\hline $1-5$ days & 44 & 54 \\
$6-10$ days & 25 & 31 \\
$11-15$ days & 07 & 09 \\
$>15$ days & 05 & 6 \\
\hline
\end{tabular}

Table 4. Distribution of patients broken down by the occurrence of complications ( $\mathrm{n}=$ $81)$.

\begin{tabular}{ccc}
\hline Complications & Number & Percentage \\
\hline $\begin{array}{c}\text { Nosocomial pneumonia acquired under } \\
\text { mechanical ventilation }\end{array}$ & 22 & 27 \\
Obstruction of the intubation tube by a plug & 10 & 12 \\
Accidental extubation & 04 & 05 \\
Pneumothorax & 02 & 02 \\
Atelectasis & 02 & 02 \\
No complications & 41 & 51 \\
\hline
\end{tabular}

39.7\%. This incidence was higher than that observed in the Comoros (15.8\%) [3] but similar to that found in the European studies (34\% in the Sennef study [5] and $41 \%$ in that of Blot [6]). This impact could be explained by the efforts made by the Ivorian health authorities to provide the intensive care unit in Treichville 
Table 5. Distribution of patients according prognostic factors $(n=81)$.

\begin{tabular}{|c|c|c|c|}
\hline \multirow{2}{*}{ Parameter } & \multicolumn{2}{|c|}{ Evolution } & \multirow{2}{*}{$\mathrm{p}$} \\
\hline & Favorable & Death & \\
\hline \multicolumn{4}{|c|}{ AGE } \\
\hline$<15$ days & 06 & 04 & \multirow{2}{*}{0.003} \\
\hline$>15$ days & 10 & 61 & \\
\hline \multicolumn{4}{|c|}{ Glasgow Score } \\
\hline$<8$ & 08 & 45 & \multirow[b]{2}{*}{0.247} \\
\hline$\geq 8$ & 08 & 20 & \\
\hline \multicolumn{4}{|c|}{ Duration of ventilation } \\
\hline$<5$ days & 09 & 21 & \multirow{2}{*}{0.136} \\
\hline$>5$ days & 07 & 44 & \\
\hline \multicolumn{4}{|c|}{ Hospital stay } \\
\hline$<7$ days & 06 & 40 & 0.145 \\
\hline$\geq 7$ days & 10 & 25 & \\
\hline \multicolumn{4}{|c|}{ Pneumonia } \\
\hline Yes & 08 & 15 & 0.067 \\
\hline No & 08 & 50 & \\
\hline \multicolumn{4}{|c|}{ Types of pathologies } \\
\hline Medical & 07 & 41 & 0.260 \\
\hline Traumatic & 09 & 24 & \\
\hline
\end{tabular}

with appropriate equipment to implement the artificial ventilation. Our study population was young with a mean age of $43.98 \pm 20.69$ years. This finding was different from that of Sennef et al., who reported older age groups over 60 years [5] because of the prevalence of pathologies such as: congestive heart failure and acute decompensations of obstructive chronic pulmonary. Pathologies requiring artificial ventilation treatment were dominated by neurological conditions such as stroke $(33 \%)$ and traumatic diseases $(28 \%)$. The predominance of stroke is explained by the fact that hospitalized patients were usually adults (over $49 \%$ of our patients were older than 45). Age is a risk factor for the occurrence of events such as stroke, resulting in neurological disorders associated with respiratory distress, which often requires patients to be placed under artificial ventilation. The mean duration of artificial ventilation was $5.98 \pm 3.73$ days. This duration was superimposable to that observed by: Ndiaye et al. [7] in Senegal (5.1 days), Seneff in the United States (4.7 days) [5], in a multicenter study performed in the West on 18,000 patients (6 days) [8]. Artificial ventilation can cause many complications when it lasts more than 48 hours [9]. Several studies have shown that respiratory infections are the first complication in patients with prolonged ventilation [10]. Nosocomial pneumonia acquired under mechanical ventilation 
constituted $27 \%$ of the complications observed in our patients. The literature evokes significantly higher figures (34\%), under significantly better material conditions of hygiene [11]. In our context, this high incidence of the nosocomial pneumonia acquired under mechanical ventilation could be explained by technical difficulties (lack of filters, difficulties of bacteriological diagnosis) and human (low training of personnel to prevent and recognize nosocomial pneumonia acquired under mechanical ventilation). Mortality among ventilated patients in our series (80\%) was higher than those observed in many studies [3] [7]. This mortality was much lower than that observed by Stauffer et al. in Europe (33\%) [12]. This could be explained on the one hand by the severity of the pathologies requiring artificial ventilation treatment of patients and on the other hand by our working conditions which was very different from that observed in many developed countries.

\section{Limitations of the Study}

The size of our study population and the fact that this work is done only within the Treichville University Hospital does not allow us to generalize the results of this preliminary study on artificial ventilation to all hospitals in Ivory Coast. However, the results of this study allow us to describe the practice of artificial ventilation in a developing country in tropical Africa and to stimulate discussion.

\section{Conclusion}

Artificial ventilation is one of the fundamental techniques of resuscitation, the practice of which is still difficult in Ivory Coast. The realization artificial ventilation in our context is at the origin of many complications dominated by nosocomial pneumopathies acquired under ventilation which could be prevented by a strict respect of the rules of hospital hygiene and a reinforcement of the capacities of the caring personnel.

\section{Declaration of Conflicts of Interest}

Authors do not declare any conflicts of interest.

\section{References}

[1] Esteban, A., Frutos-Vivar, F., Muriel, A., Ferguson, N.D., Peñuelas, O., et al. (2013) Evolution of Mortality over Time in Patients Receiving Mechanical Ventilation. American Journal of Respiratory and Critical Care Medicine, 188, 220-230. https://doi.org/10.1164/rccm.201212-2169OC

[2] Wunsch, H., Linde-Zwirble, W.T., Angus, D.C., Hartman, M.E. and Milbrandt, E.B. (2010) The Epidemiology of Mechanical Ventilation Use in the United States. Critical Care Medicine, 38, 1947-1953. https://doi.org/10.1097/CCM.0b013e3181ef4460

[3] Durasnel, P., Gallet De Santerre, P., Merzouki, D., Ridhoine, M., Charif, M., et al. (2005) Faut-il ventiler les patients de réanimation dans les pays en développement? 
Med Trop, 65, 537-542.

[4] Slutsky, A.S. and Ranieri, V.M. (2013) Ventilator-induced Lung Injury. The New England Journal of Medicine, 369, 2126-2136.

https://doi.org/10.1056/NEJMra1208707

[5] Sennef Michael, G., Zimmerman Jack, E., Knaus William, A., Wagner Douglas, P., Draper Elisabeth, A., et al. (1996) Predicting Duration of Mechanical Ventilation: The Importance of disease And Patient Characteristics. Chest, 110, 469-479. https://doi.org/10.1378/chest.110.2.469

[6] Blot, F. (2003) Etude de l'intérêt de la trachéotomie précoce chez les malades sous ventilation mécanique prolongée. Revue des Maladies Respiratoires, 20, 411-420.

[7] Ndiaye, M., Wade, K., Niang, B., Kone/Mbodj, M., Mbow, C., et al. (2005) Pneumopathies acquises sous ventilation mécanique: Résultats d'une étude réalisée dans le service de réanimation de l'HPD. SRLF: Réanimation, 14, 118.

[8] Esteban, A., Frutos, F., Tobin, M.J., Alia, I. and Solsona, J.F. (1995) A Comparison of Four Methods of Weaning Patients from Mechanical Ventilation. Spanich Lung Failure Collaborative Group. The New England Journal of Medicine, 332, 345-350. https://doi.org/10.1056/NEJM199502093320601

[9] Craven, D.E., Barber, T.W., Sterger, K.A. and Montecalvo, M.A. (1990) Nosocomial Pneumonia in the 1990's: Update of Epidemiology and Risk Factors. Seminars in Respiratory Infections, 5, 157-172.

[10] Brun-Buisson, C. (2000) Prévention des pneumopathies nosocomiales. Actualités en réanimation et urgence. SRLF Edition Elsevier, 41-55.

[11] Chastre, J. and Fagon, J.Y. (2002) Ventilator-Associated Pneumonia. American Journal of Respiratory and Critical Care Medicine, 165, 867-872. https://doi.org/10.1164/ajrccm.165.7.2105078

[12] Stauffer, J.L., Fayter, N.A., Graves, B., Cromb, M., Lynch, J.C., et al. (1993) Survival Following Mechanical Ventilation for Acute Respiratory Failure in Adult Men. Chest, 104, 1222-1229. https://doi.org/10.1378/chest.104.4.1222 